\title{
Novel colorectal endoscopic in vivo imaging and resection practice: a short practice guide for interventional endoscopists
}

Received: 21 September 2006 / Accepted: 19 November 2006 / Published online: 16 February 2007

(C) 2007 The Authors ${ }^{1}$

\begin{abstract}
Colorectal cancer remains a leading cause of cancer death in the UK. With the advent of screening programmes and developing techniques designed to treat and stage colorectal neoplasia, there is increasing pressure on the colonoscopist to keep up to date with the latest practices in this area. This review looks at the basic principles behind endoscopic mucosal resection and forward to the potential endoscopic tools, including high-magnification chromoscopic colonoscopy, high-frequency miniprobe ultrasound and confocal laser scanning endomicroscopic colonoscopy, that may soon become part of routine colorectal cancer management.
\end{abstract}

Key words Colonoscopy • Endoscopic mucosal resection • Colorectal cancer

${ }^{1}$ This is a "Springer Open Choice" article. Unrestricted non-commercial use, distribution and reproduction in any medium are permitted, provided the original author and source are credited.

R.J. Atkinson • D.P. Hurlstone (两)

Department of Endoscopy

Royal Hallamshire Hospital

Sheffield, UK

E-mail: p.hurlstone@shef.ac.uk

\section{A.J. Shorthouse}

Department of Colorectal Surgery

Northern General Hospital

Sheffield, UK

\section{Introduction}

Colorectal cancer (CRC) remains one of the leading causes of cancer death in the West and in 2002 is estimated to have affected 148000 and 22000 people in the USA and UK, respectively $[1,2]$. CRC develops in $5 \%-6 \%$ of the adult population, and almost $50 \%$ die as a consequence of the disease $[3,4]$. Colonoscopy is now widely accepted as the gold standard for the early detection of colorectal cancer with evidence to support a direct mortality reduction in cohorts undergoing screening sigmoidoscopy [5, 6]. Furthermore, total colonoscopy has been shown to reduce the incidence of colorectal cancer in patients with adenomatous polyps [7]. These data support the effectiveness of colonoscopy for the detection of CRC and polypectomy in the secondary prevention of CRC. Furthermore, the prognosis of patients with $\mathrm{CRC}$ is dependent on the early detection of disease, with $95 \%$ and $<50 \%$ 5-year survivals observed in patients with stage T1 and T3/4 disease, respectively [8]. Data from Japan [9] and our group in the UK [10-12] now suggest that stage Tim/1 disease can be curatively treated using novel endoluminal resection techniques such as endoscopic mucosal resection (EMR) and endoscopic submucosal dissection (ESD). However, despite these data, evidence to suggest failure in secondary prevention of CRC by total colonoscopy and polypectomy is emerging [13-15]. Many reasons may account for these data [16-19]. Importantly, new endoscopic techniques such as chromoscopic colonoscopy and high-magnification chromoscopic colonoscopy (HMCC) have highlighted the clinical importance of flat and depressed non-polypoid colorectal lesions which until recently were believed to be a purely Japanese phenomena know as 'phantom carcinoma' or Akita's disease [19]. Such lesions are difficult to detect using conventional white light colonoscopic techniques and barium studies, but have significant clinicopathological characteristics [20]. Clinically, such lesions have now been shown to have a significant prevalence within Western cohorts [21-25]. Data 
from centres outside Japan now suggest that novel endoscopic resection techniques such as EMR and ESD are applicable to Western endoscopic practice.

\section{Endoscopic mucosal resection}

Following the initial description of EMR or the 'strip biopsy technique' by Dehyle et al. [26], EMR has been developed by Japanese endoscopists for the resection of sessile and flat lesions of the stomach, oesophagus and colorectum [27]. For pedunculated lesions this technique is not required, as simple snare resection is adequate. EMR permits the resection of flat and sessile lesions by longitudinal section through the submucosal layer [28]. In the colorectum, EMR may provide curative resection for flat and sessile adenomas in addition to early colorectal cancer [28]. For lesions less than $20 \mathrm{~mm}$ diameter, en-bloc EMR facilitates complete histological analysis of the resected lesion and makes it possible to determine precisely the completeness of excision in both the horizontal and vertical resection planes [29]. Complete excision may be possible in the majority of cases, with $\mathrm{R} 0$ resection rates as high as $96 \%$ being described [30]. For lesions greater than $20 \mathrm{~mm}$ diameter, historically piecemeal dissection has been required. The principle limitation to piecemeal dissection is the inability to assess the vertical and horizontal resection margins with lesions defaulting at histopathological analysis to Rx (margins not discernable). However, rates for en bloc resection and en bloc plus histopathologically confirmed R0 status of $88.6 \%$ and $62.9 \%$, respectively, by ESD have now been described in Western practice and are comparable to the preliminary data from Japan [29]. Such endoscopic resection techniques are preferable to primary tissue ablation such as argon plasma coagulation [31] and electrocoagulation [32] as a definitive histopathological specimen guides subsequent endoscopic and clinical management in the majority of cases. Numerous EMR techniques have now been described which include the lift and cut technique, traction-assisted resection, and that using a transparent cap fitted to the proximal aspect of the endoscope [33] in conjunction with an insulation-tipped cutting knife [34]. While these techniques are primarily reserved for resection of oesophageal, gastric and submucosal posterior rectal tumours $[27,34]$, ESD has now been shown to be both safe and feasible for the resection of tumours up to and beyond the splenic flexure [35] although this remains a developmental technique not in routine practice at many centres in Europe.

\section{Basic EMR technique}

The technique of EMR (Fig. 1) comprises 4 stages:

1. Diagnosis and localisation of the lesion.

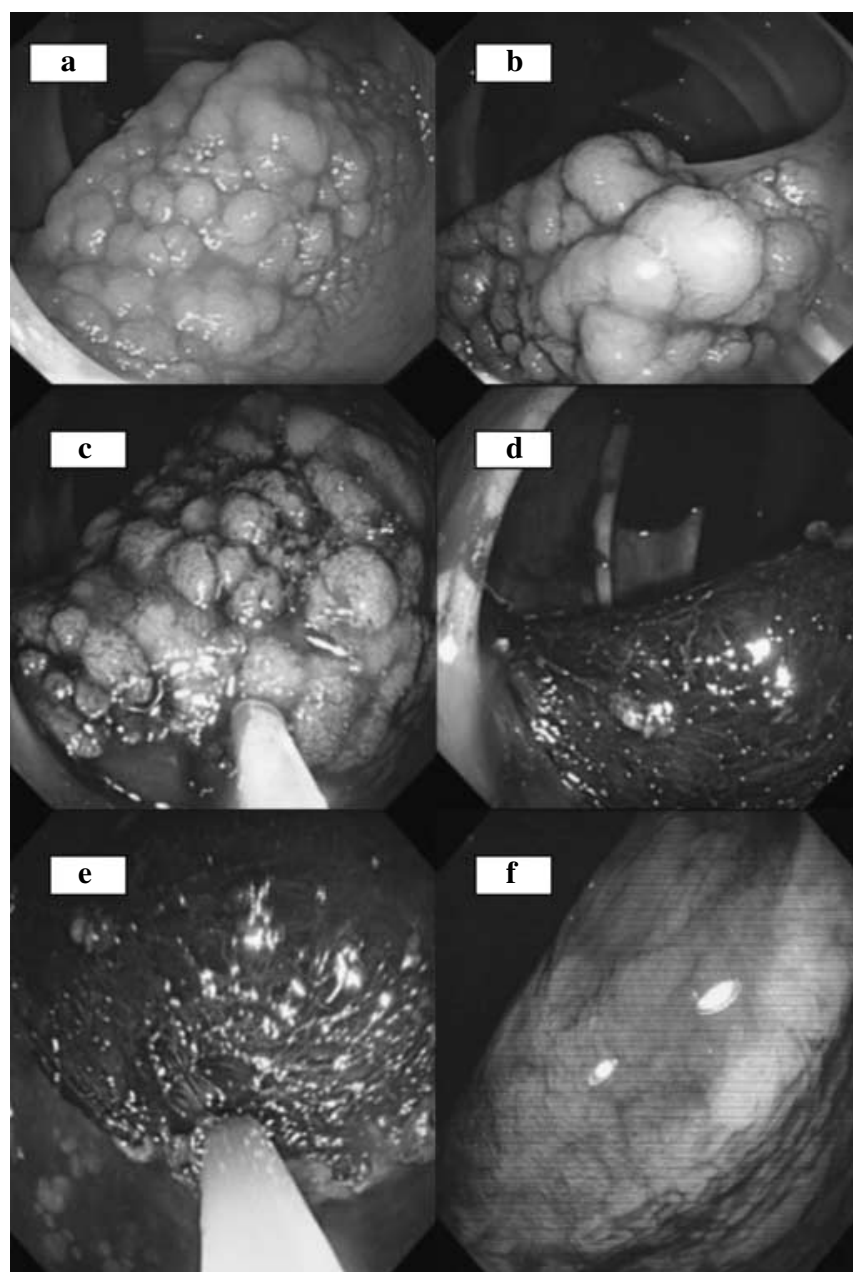

Fig. 1a-f Endoscopic mucosal resection (EMR). a A G-type lateral spreading tumour of the ascending caecal junction viewed in full retroflexion. b Indigo carmine $(0.5 \%)$ chromoscopy clearly delineates the tumour margins and nodularity. c Submucosal cannulation provides a symmetrical and sustained 'lift' prior to submucosal dissection. d The exposed post-dissection 'stranding' of the muscularis can be clearly identified following assessment of the postresection margins using indigo carmine chromoscopy. e Argon plasma ablation is applied to the circumferential margins of the resection. f Endoscopic appearances of the lesion 12 weeks after resection. There is complete epithelial restoration with a mucosal type I crypt pattern. Curative resection has been achieved

2. Evaluation of invasive depth to exclude lesions invading the deep submucosal layer 3 or beyond (i.e. T2 disease) using HMCC or ultrasonography (US).

3. Excision procedure.

4. Post-resection evaluation.

Initial diagnosis and location of flat and sessile lesions of the colorectum are facilitated by the use of indigo carmine (IC) chromoscopy, which allows observation of detailed morphology [9]. Lesions should then be described according to Paris Workshop guidelines (Table 1). Narrow band imaging (NBI) is an alternative technique in which modified optical filters are used in the light source of the 
Table 1 Paris Workshop guidelines [56] for the gross morphological classification of colorectal lesions

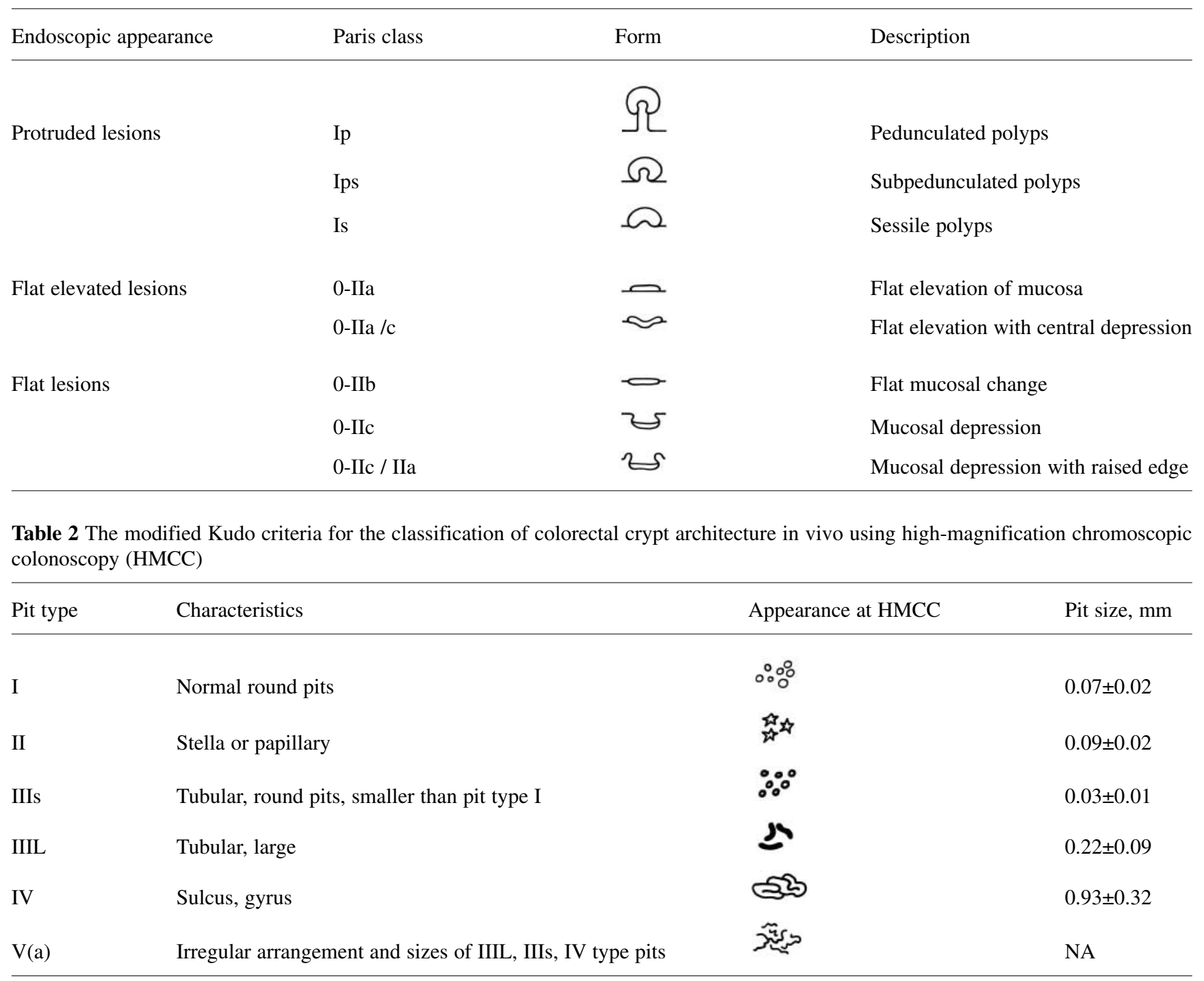

$N A$, not applicable

video-endoscope system to provide 'virtual chromoscopy'. Provisional data suggest comparable rates of diagnostic accuracy of NBI $[36,37]$ to IC chromoscopy. Further randomised controlled trials are now required to clarify this issue prior to implementation of NBI into routine clinical practice.

In vivo staging of lesions can be achieved using HMCC (Table 2) [38], the Olympus Lucera differential of haemaglobin indices function (Hib) (Olympus Lucera, Tokyo, Japan) for vascular ectasia mapping and through-the-scope miniprobe US (12.5-20 MHz), either alone or as a multimodality technique (Table 3) [39]. Flat and sessile lesions up to $20 \mathrm{~mm}$ in diameter can be resected by en bloc or 'single pass' resection, but larger lesions usually require a piecemeal approach [29]. A needle catheter is then inserted through the side port of the colonoscope with sterile saline or an alternative submucosal solute (e.g. sodium hyaluronic acid, glycerol, 50\% dextrose solution) injected peripherally and centrally into the lesion and surrounding mucosa. A cleavage of the submucosa (having the effect of raising the lesion) then permits simple snare resection. A single cannulation can be used for small lesions $(<10 \mathrm{~mm}$ diameter) with multiple cannulations usually required for lesions of $20 \mathrm{~mm}$ or more [29]. Some authors advocated the use of adrenaline (1:100 000) mixed with saline or twice-normal saline at submucosal injection to maintain a 'dry' dissection field [40]. 50\% dextrose solution was shown to provide a longer duration of lift, with smaller injection volumes and higher rates of en-bloc resection, although there were no differences in completeness of resection or complications in the total cohort in Varadarajulu et al.'s study [41]. Other studies have utilised a number of solutes including hyaluronic acid, hydroxypropyl methylcellulose and glycerol, with demonstrably 
Table 3 Clinical criteria for submucosal invasive depth estimation using four different diagnostic imaging techniques

\begin{tabular}{lllll}
\hline Histopathology & HMCC & Hib vascular ectasia mapping & $\begin{array}{l}\text { Combined HMCC and } \\
\text { vascular ectasia mapping }\end{array}$ & $\begin{array}{l}\text { High-frequency miniprobe } \\
\text { endoscopic US }\end{array}$ \\
\hline Tis/sm1 & $\begin{array}{l}\text { Crypt A: } \\
\text { crypt fully defined }\end{array}$ & Normal vascular pattern & $\begin{array}{l}\text { Crypt A + normal } \\
\text { vascular pattern }\end{array}$ & $\begin{array}{l}\text { Hypoechoic mass within } \\
\text { first hypoechoic layer }\end{array}$ \\
sm2 & $\begin{array}{l}\text { Crypt B: } \\
\text { crypt partially defined }\end{array}$ & $\begin{array}{l}\text { Vessel tortuosity } \\
\text { with dilatation }\end{array}$ & $\begin{array}{l}\text { Crypt B + vessel } \\
\text { tortuosity with dilatation }\end{array}$ & $\begin{array}{l}\text { Hypoechoic mass } \\
\text { infiltrating second } \\
\text { hypoechoic layer }\end{array}$ \\
& $\begin{array}{l}\text { Crypt C: } \\
\text { crypt not defined } \\
\text { or absent }\end{array}$ & $\begin{array}{l}\text { Complete disruption of } \\
\text { vascular architecture }\end{array}$ & $\begin{array}{l}\text { Crypt C + complete } \\
\text { disruption of vascular } \\
\text { architecture }\end{array}$ & $\begin{array}{l}\text { Hypoechoic mass } \\
\text { infiltrating third layer } \\
+/- \text { extension to hyperechoic } \\
\text { muscularis }\end{array}$ \\
\hline
\end{tabular}

$U S$, ultrasonography

better and longer lasting mucosal lift [42-44]. However, no randomised controlled trial has proved superiority with regard to resection clearance (with specific reference to R0 resection rates), post-EMR haemorrhage or perforation. Whatever injection medium used, it is essential to maintain a sufficient mucosal lift or detachment throughout the dissection, which minimises the risk of the muscularis propria being trapped within the vertical resection plane of the snare and subsequent perforation [27].

After resection, evaluation of the mucosal defect is mandatory, as remnant neoplastic tissue continues to assume an overall risk of progression to invasive neoplasia. Complete resection in the horizontal axis can be determined using IC chromoscopy by the identification of a normal type I pit pattern (as defined by the modified Kudo criteria [38]). Remnant neoplastic tissue (as identified by Kudo crypt types IIIL, IV or V) suggests R1 resection status and should prompt the endoscopist to extend the initial resection or employ an adjunctive ablative technique such as APC to the positive resection margins [45]. The Sheffield group advocate peripheral margin tattoos prior to submucosal injection that delineates the normal mucosal boundaries around the lesion prior to resection [46]. This technique may facilitate $\mathrm{R} 0$ resection, as at submucosal lift, the lesion can become distorted and indistinct from the surrounding normal mucosa [46]. If the lesion fails to lift (the non-lifting sign of Uno) or has an asymmetrical appearance, then the resection should be abandoned as this indicates tethering to the underlying muscularis mucosa [47]. Perforation and risk of non-curative resection can occur in this scenario [47, 48]. All lesions should have an adjacent submucosal tattoo applied using India ink or 'Endo Spot' endoscopic marker [Ref: GIS-44, Camp Hill, PA 17011] to facilitate localisation at follow-up colonoscopy or subsequent surgical resection [49].
Following successful submucosal lift, a spiked or 'barbed' snare is applied over the lesion and slowly closed under gentle suction [27]. This permits the lesion to be retained within the snare boundaries before final resection [27]. Prior to final cutting (usually using a $25 \mathrm{~W}$ or $10 \mathrm{~W}$ coagulation current for lesions distal or proximal to the splenic flexure, respectively), the snare should be relaxed slightly to allow any entrapped muscularis mucosa to retract [27]. Following resection, the lesion should be retrieved using pronged grasping forceps or preferably a Roth net which limits tissue trauma to the specimen, prior to 'pinning out' and immediate fixation in $10 \%$ formalin solution. Japanese endoscopists 'pin out' the lesion onto a solid cork or polystyrene plate prior to fixation, which limits shrinkage of the resection specimen and permits easier and more accurate histopathological sectioning [34].

\section{Complications of EMR}

The main complications of EMR are haemorrhage, perforation and stenosis $[49,50]$. The immediate and early complications ( $10 \%$ of cases) described in the first 12 hours after resection are principally haemorrhage and rarely perforation [50]. The Sheffield group reported bleeding complications in only $2 \%$ of patients undergoing EMR in their cohort of 599 lesions [10], which was significantly lower than that reported in Ahmed et al.'s retrospective analysis $(22 \%)$ [51]. However, other Japanese authors have reported haemorrhage rates after colonic EMR of 1.16\% (10 of 863) [52], comparable to those observed in the Sheffield series [10]. Okamoto et al.'s review of interventional colonoscopic resections also reported a perforation rate secondary to EMR of only $0.35 \%$ [50], and Kaneko et al.'s multicentre analysis of endoscopic mortality showed rates 
of less than $0.0001 \%$ for this procedure [53]. In Hurlstone et al.'s evaluation of 599 EMR procedures, no patient required emergency laparotomy for bleeding or perforation, whilst $15(2.5 \%)$ had incomplete vertical excision margins with 9 requiring surgical excision $(<1 \%)$ at a median of 3.5 years follow-up [10]. EMR may therefore be a safe and effective endoscopic therapy that may enhance our current strategies aimed at the secondary prevention of colorectal cancer.

\section{Endoscopic submucosal dissection}

ESD allows en bloc knife dissection of lesions usually in excess of $20 \mathrm{~mm}$ diameter to the vertical depth of the muscularis mucosa $[54,55]$. Determination of the morphological class by chromoscopic colonoscopy as per the Paris consensus criteria [56] and on-table staging of the lesion by high-frequency ultrasound (HFUS) with differentiation of tumour stage and nodal disease status as per the Cho criteria [57] enables accurate assessment as to the feasibility of ESD. Lesions with a fixed Paris type IIc component (defined as a fixed depression whether air is insufflated or deflated) or Cho criteria for $\mathrm{T} 2 / \mathrm{N} 1$ disease are not amenable to ESD (Fig. 2). Following submucosal catheterisation and lifting with either sodium hyaluronic acid or glycerol submucosal infiltration, circumferential mucosal incisions are made at 5- to 6-mm intervals around the pancircumference of the lesion. Submucosal dissection can then be initiated from the most proximal aspect of the lesion using the insulation-tipped knife. Maintenance of the dissection plane, by patient manoeuvring, in addition to direct tissue traction from the distally attached endoscopic dissection assistance cap, enables visualisation of the exposed muscularis layer and reduces the risk of per- foration. The resected specimen can be retrieved by Roth net and then pinned out (to reduce shrinkage) before undergoing histological assessment for resection completeness (i.e. R stage).

\section{Complications of ESD}

As with EMR, the main complications include haemorrhage and perforation $[54,55,58,59]$ with Fujishiro et al. [59] reporting a bleeding rate of $12 \%$ and an overall perforation rate of $5.7 \%$ ( 2 of 35 ). However, in this series, both perforations were treated conservatively without need for surgical intervention [59]. The learning curve and optimal teaching modality for ESD have not yet been described in the literature, but this is now required should this novel yet technically demanding endoscopic technique become adopted outside of tertiary referral practice.

\section{Evolving technology for the future}

\section{Magnification chromoscopy}

Accurate in vivo staging is essential at colonoscopy prior to consideration of local endoluminal resection. Flat focal submucosal invasive CRCs which are limited to the submucosal layer 1 can be managed by EMR as the risk of lymphovenous invasion and nodal metastasis is low $(<5 \%)$ [60-62]. For lesions with deeper vertical invasion into the submucosal layer 3 or beyond (stage T2), the risk of nodal disease increases to $10 \%-15 \%$ [63]. EMR in this group is therefore undesirable due to a higher risk of perforation, non-curative excision and untreated nodal disease [28].

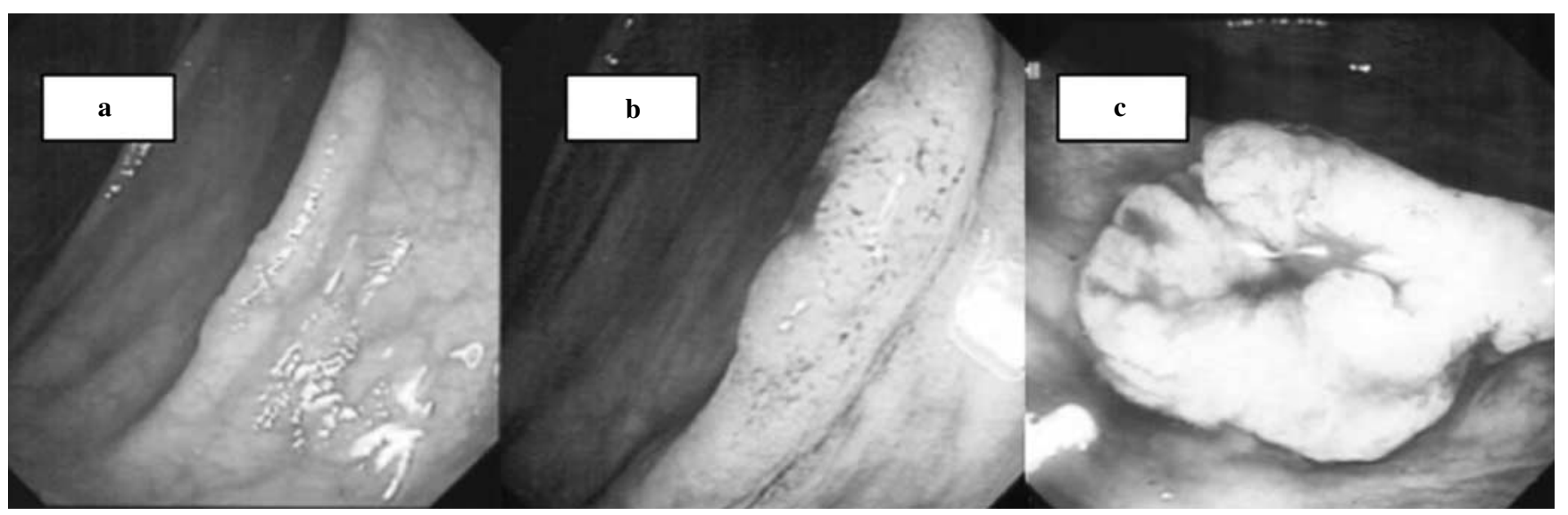

Fig. 2a-c Lesion with a fixed Paris type IIC component not amenable to endoscopic submucosal dissection (ESD). a Nodularity of fold noted using conventional colonoscopy in the mid-ascending colon. b Indigo carmine $(0.5 \%)$ chromoscopy shows a diminutive Paris type 0 -II lesion. c Zoom view at 30x magnification shows a clear type 0-IIc depressed component to the lesion. An invasive adenocarcinoma (stage T2/N0) was evident at post-surgical resection histopathology 


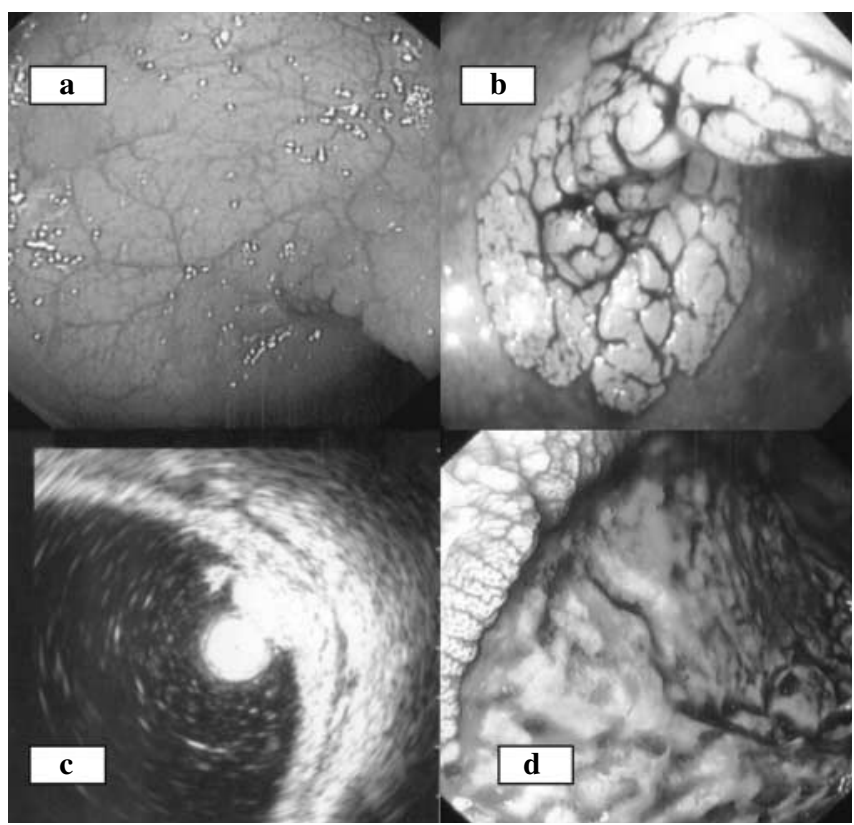

Fig. 3a-d High-frequency miniprobe ultrasonography. a Focal erythema and nodularity present in the distal sigmoid colon at conventional endoscopy. b Indigo carmine (0.5\%) chromoscopy delineates a flat Paris type 0-IIa lateral spreading tumour. c High-frequency 'through the scope' miniprobe $12.5 \mathrm{MHz}$ endoscopic ultrasound shows bluring of the submucosal layer $1 / 2$ but a preserved muscularis (thick adjacent hyperechoic band). There is no associated per-colic lymphadenopathy. Endoscopic submucosal dissection is indicated given the 'on-table stage' of Tim/NO. d Endoscopic view of the lesion 1 month after resection. Note the granulation tissue present at the resection base with a surrounding normal type I crypt architecture. Curative resection was achieved

Surgical excision is recommended in this group [28, 34].

Chromoscopic colonoscopy used as an in vivo staging tool has been reported by Saitoh et al. [64]. In this retrospective analysis of depressed type early CRCs, combined video-endoscopy and chromoscopy was used to characterise the essential endoscopic features favoured by lesions with submucosal layer 1 and 2 invasion, which at the time of endoscopy may be used as a tool to guide the colonoscopic management (i.e. attempted EMR or biopsy alone with surgical referral) [64]. Using Saitoh et al.'s criteria (expansion appearance, present; surface depression, deep; irregularity of depressed surface, uneven; and converging folds toward the tumour), the sensitivity and specificity for determining submucosal layer 2 disease were both $90 \%$ [64]. However, when 21 lesions showing intramucosal carcinoma were excluded from the analysis, specificity fell to $70 \%$ [64]. In Hurlstone et al.'s prospective analysis of endoscopic morphological anticipation of submucosal invasion in flat and depressed lesions [65] using the Nagata subtype analysis [66] of the Kudo type V pit pattern [38], the K coefficient of agreement between pit type $\mathrm{V}$ and histologically confirmed $\mathrm{sm} 2$ invasion was 0.51 . Using pit types $\mathrm{Vn}(\mathrm{B})$ and $\mathrm{Vn}(\mathrm{C})$ as clinical indicators of invasive disease, $97 \%$ of lesions was correctly anticipated to have sm2+ invasion; however, specificity was low at $50 \%$ (overall accuracy, 78\%) [65]. Similar problems have been encountered using the $7.5 \mathrm{MHz}$ ultrasound probe in the staging of rectal carcinoma, with variable accuracy rates reported (from $60 \%$ to $79 \%$ ) according to the T stage system [67, 68]. High-frequency $20 \mathrm{MHz}$ 'miniprobe' ultrasound has now been reported to have a high overall accuracy when used to determine submucosal invasion for flat and depressed lesions (Fig. 3) [69] with 93\% accuracy in determining invasive depth staging and $80 \%$ sensitivity for predicting lymph node metastasis [70]. However, ultrasound imaging requires further training, has significant expense and may prolong the procedure [70].

In summary, the limitations of HMCC technology are: - High sensitivity and specificity for the differentiation of non-neoplastic from neoplastic disease, but low overall sensitivity for the anticipation of high-grade dysplasia.

Effective over-staging of submucosal layer 3 / T1 neoplasia.

- Significant operator-dependent error.

\section{Autofluorescence colonoscopy}

Chromoscopic and high-magnification techniques have been introduced in an attempt to improve the sensitivity and specificity of 'white-light' colonoscopy. However, a new endoscopic technology that is fluorescence-based is under evaluation by many groups [71, 72]. This technology exploits either the autofluorescence of naturally occurring molecules, such as collagen, NAD-H, flavins and porphyrins, or the fluorescence of exogenously administered fluorescent drugs.

The detection of neoplastic lesions using autofluorescence depends on subtle changes in the concentration or distribution in depth of endogenous fluorophores, changes in tissue micro-architecture and altered mucosal thickness or blood concentrations [73]. All these factors affect the fluorescence intensity or spectrum due to wavelength-specific light absorption [73]. Using exogenous fluorophores, the detection of lesions is based on selective drug uptake or target tissue retention relative to uptake by normal tissue [73].

Kapadia et al. used ultraviolet (UV) light in the colon to discriminate normal mucosa, adenomas and hyperplastic lesions with accuracies of $100 \%, 100 \%$ and $94 \%$, respectively [72]. In the first in vivo human colonic spectroscopic study by Cothren et al., differentiation between adenoma and non-adenomatous lesions was achieved in $97 \%$ of cases [74]. Cothren et al. in the first blinded study also identified colonic dysplasia with $90 \%$ sensitivity and 95\% specificity [75].

However, the clinical potential of spectroscopy in routine endoscopic practice has not yet been clarified. 
Chwirot et al. performed multi-spectral autofluorescence imaging in the colon of polyps ex vivo [76], and Wang et al. recently described a prototype fluorescence imaging system applied ex vivo to detect and localise adenomas in colectomy specimens from patients with familial adenomatous polyposis [77]. A second-generation fluorescence imaging system was described by Wang et al. in 1999 for the in vivo detection of colorectal adenomas in which UV light was transmitted through a fibre-optic bundle inserted through the side port of the endoscope [78]. A videocolonoscope was then used to capture the fluorescence light within the wavelength band 400-700 nm [78]. Falsecolour images were then overlaid onto the conventional white-light images, displaying regions where the fluorescence intensity exceeded threshold values relative to a moving image [78]. In this study of 30 patients, 18 lesions visible with white-light imaging were examined, all 6 hyperplastic lesions were correctly identified, and the sensitivity for dysplasia was $83 \%$ [78]. However, despite these encouraging initial data, further studies are required before such technology can be implemented in routine endoscopic clinical practice.

\section{Confocal laser endomicroscopic colonoscopy}

Given the limitations of HMCC and autofluorescence, laser scanning confocal microscopy (LCM) has recently been developed as an alternative means of in vivo histopathological diagnosis. LCM is an adaptation of light microscopy whereby focal laser illumination is combined with 'pinhole limited detection' to geometrically reject out of focus light. In single-point scanning confocal microscopes, the point is typically scanned in a raster pattern and measurements of light returning to the detector from successive points are digitized so an image of the scanned

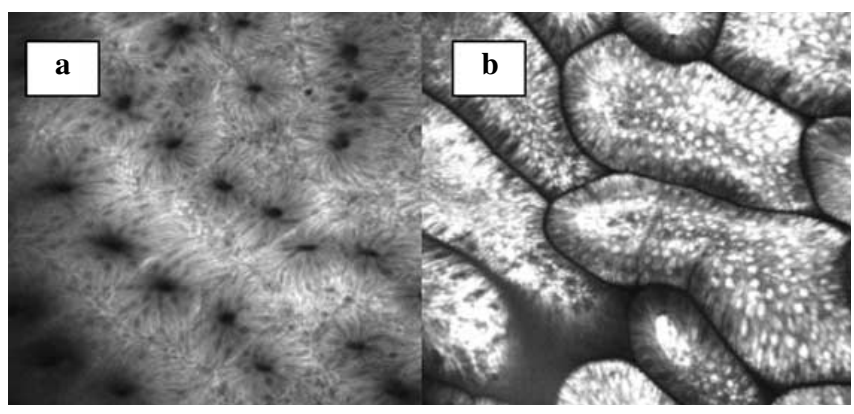

Fig. 4 a, b Confocal laser endomicroscopic colonoscopy. a Normal rectal mucosa. Note the halo or peri-cryptic goblet cells. b Normal terminal-ileum. Note the brush border containing goblet cells interspersed with columnar epithelium. The central crypt has a single capillary with erythrocytes visible within. The surrounding peristromal cellular architecture traverses the interface between the brush border and vascular net region can be constructed. Each resultant image is an 'optical section' representing approximately one focal plane within the specimen (Fig. 4).

The components of the laser confocal colonoscope are based on the integration of a confocal laser microscope mounted in the tip of a conventional colonoscope (EC3870K; Pentax, Tokyo, Japan), which enables confocal microscopy in addition to standard videoendoscopy. During LCM, an argon ion laser delivers light at an excitation wavelength of $488 \mathrm{~nm}$ with a maximum laser output of $<1 \mathrm{~mW}$ at the surface mucosa. Confocal images can then be collected at a scan rate of 0.8 frames per second (1024x1024 pixels) or 1.6 frames per second (1024x512 pixels). The optical slice thickness is $7 \mu \mathrm{m}$ with a lateral resolution of $0.7 \mu \mathrm{m}$ and a $\mathrm{z}$-axis range of $0-250 \mu \mathrm{m}$ below the surface layer.

\section{Conclusions}

There is much further potential for evolving practice and research at the present time. The key areas at present we perceive are:

- Early cancer detection and intraepithelial neoplasia detection in sporadic colorectal cancer and chronic ulcerative colitis.

- Targeted "smart" biopsies using confocal laser scanning endomicroscopy. This technique would optimise the yield of high quality biopsies being interpreted by histopathologists and confer significant economic benefits.

- Advanced endoscopic resection practice.

This review shows that emerging concepts in endoscopic detection and therapeutic techniques, initially pioneered by the Japanese, are applicable to Western practice. We hope that chromoscopic colonoscopy and magnification imaging in addition to EMR will now be more widely practiced by both surgical and medical gastroenterologists. However, while differences remain between Japanese and Western classification systems it is difficult to extrapolate endoscopic and pathological data reported in Japanese studies to our practice. Furthermore, additional studies are required to clarify the role of chromoscopic colonoscopy and magnification imaging in routine clinical practice. Confocal endomicroscopy may change the in vivo diagnostic paradigm once again. Finally, all practitioners require further education and training, if new diagnostic techniques and therapeutic procedures are to be adopted.

\section{References}

1. Ciccolallo L, Capocaccia R, Coleman MP et al (2005) Survival differences between European and US patients with 
colorectal cancer: role of stage at diagnosis and surgery. Gut $54: 268-273$

2. Gatta G, Ciccolallo L, Capocaccia R et al (2003) Differences in colorectal cancer survival between European and US populations: the importance of sub-site and morphology. Eur J Cancer 39:2214-2222

3. Weir HK, Thun MJ, Hankey BF et al (2003) Annual report to the nation on the status of cancer, 1975-2000, featuring the uses of surveillance data for cancer prevention and control. J Natl Cancer Inst 95:1276-1299

4. Ries LA, Wingo PA, Miller DS et al (2000) The annual report to the nation on the status of cancer, 1973-1997, with a special section on colorectal cancer. Cancer 88:2398-2424

5. Atkin WS, Cuzick J, Northover JMA et al (1993) Prevention of colorectal cancer by once-only sigmoidoscopy. Lancet 341:736-740

6. Atkin WS, Morson BC, Cuzick J (1992) Long-term risk of colorectal cancer after excision of rectosigmoid adenomas. $\mathrm{N}$ Engl J Med 326:658-662

7. Atkin WS (1999) Implementing screening for colorectal cancer. BMJ 319:1212-1213

8. Berrino F (1995) Survival of cancer patients in Europe: the Eurocare study. International Agency for Research on Cancer, Lyon

9. Kudo S, Kashida H, Tamura T et al (2000) Colonoscopic diagnosis and management of nonpolypoid early colorectal cancer. World J Surg 24:1081-1090

10. Hurlstone DP, Cross SS, Adam I et al (2004) An evaluation of colorectal endoscopic mucosal resection using high-magnification chromoscopic colonoscopy: a prospective study of 1000 colonoscopies. Endoscopy 36:491-498

11. Hurlstone DP, Cross SS, Adam I et al (2004) Efficacy of high magnification chromoscopic colonoscopy for the diagnosis of neoplasia in flat and depressed lesions of the colorectum: a prospective analysis. Gut 53:284-290

12. Hurlstone DP, Sanders DS, Cross SS et al (2004) Colonoscopic resection of lateral spreading tumours: a prospective analysis of endoscopic mucosal resection. Gut 53:1334-1139

13. Robertson DJ, Greenberg ER, Beach M et al (2005) Colorectal cancer in patients under close colonoscopic surveillance. Gastroenterology 129:34-41

14. Winawer SJ, Zauber AG, Ho MN et al (1993) Prevention of colorectal cancer by colonoscopic polypectomy. The National Polyp Study Workgroup. N Engl J Med 329:1977-1981

15. Muller AD, Sonnenberg A (1995) Prevention of colorectal cancer by flexible endoscopy and polypectomy. A case-control study of 32,702 veterans. Ann Intern Med 123:904-910

16. Hixson LJ, Fennerty MB, Sampliner RE et al (1990) Prospective study of the frequency and size distribution of polyps missed by colonoscopy. J Natl Cancer Inst 82:1769-1772

17. Rex DK, Cutler CS, Lemmel GT et al (1997) Colonoscopic miss rates of adenomas determined by back-to-back colonoscopies. Gastroenterology 112:24-28

18. Hurlstone DP, Cross SS, Slater R et al (2004) Detecting diminutive colorectal lesions at colonoscopy: a randomised controlled trial of pan-colonic versus targeted chromoscopy. Gut 53:376-380

19. Hurlstone DP, Fujii T, Lobo AJ (2002) Early detection of colorectal cancer using high-magnification chromoscopic colonoscopy. Br J Surg 89:272-282
20. Kudo S (1993) Endoscopic mucosal resection of flat and depressed types of early colorectal cancer. Endoscopy 25:455-461

21. Rembacken BJ, Fujii T, Cairns A et al (2000) Flat and depressed colonic neoplasms: a prospective study of 1000 colonoscopies in the UK. Lancet 355:1211-1214

22. Hurlstone DP, Cross SS, Adam I et al (2003) A prospective clinicopathological and endoscopic evaluation of flat and depressed colorectal lesions in the UK. Am J Gastroenterol 98:2543-2549

23. Suzuki N, Talbot IC, Saunders BP. (2004) The prevalence of small, flat colorectal cancers in a western population. Colorectal Dis 6:15-20

24. Tsuda S, Veress B, Toth E et al (2002) Flat and depressed colorectal tumours in a southern Swedish population: a prospective chromoendoscopic and histopathological study. Gut 51:550-555

25. Saito Y, Waxman I, West AB et al (2001) Prevalence and distinctive biological features of flat colorectal adenomas in a North American population. Gastroenterology 120:1657-1665

26. Deyhle P, Largader F, Jenny S et al (1973) A method for endoscopic electroresection of sessile colonic polyps. Endoscopy 5:38-40

27. Rembacken BJ, Gotoda T, Fujii T et al (2001) Endoscopic mucosal resection. Endoscopy 33:709-718

28. Kudo S, Tamegai Y, Yamano H et al (2001) Endoscopic mucosal resection of the colon: the Japanese technique. Gastrointest Endosc Clin N Am 11:519-535

29. Kudo S, Tamura S, Kashida H et al (1996) Endoscopic treatment in colorectal lesions-especially on endoscopic mucosal resection. Nippon Rinsho 54:1298-1306

30. Hurlstone DP, Cross SS, Brown S et al (2004) A prospective evaluation of high-magnification chromoscopic colonoscopy in predicting completeness of EMR. Gastrointest Endosc 59:642-650

31. Brooker JC, Saunders BP, Shah SG et al (2002) Treatment with argon plasma coagulation reduces recurrence after piecemeal resection of large sessile colonic polyps: a randomised trial and recommendations. Gastrointest Endosc 55:371-375

32. Lambert R, Provenzale D, Ectors N et al (2001) Early diagnosis and prevention of sporadic colorectal cancer. Endoscopy 33:1042-1064

33. Inoue H, Takeshita K, Hori H et al (1993) Endoscopic mucosal resection with a cap-fitted panendoscope for esophagus, stomach, and colon mucosal lesions. Gastrointest Endosc 39:58-62

34. Rembacken BJ, Fujii T, Kondo H. (2001) The recognition and endoscopic treatment of early gastric and colonic cancer. Best Practice Res Clin Gastroenterol 15:317-336

35. Fujishiro M, Yahagi N, Nakamura M et al (2006) Endoscopic submucosal dissection for rectal epithelial neoplasia. Endoscopy 38:493-497

36. Machida H, Sano Y, Hamamoto Y et al (2004) Narrow-band imaging in the diagnosis of colorectal mucosal lesions: a pilot study. Endoscopy 36:1094-1098

37. Chiu HM, Chang CY, Chen CC et al (2006) A prospective comparative study of narrow-band imaging, chromoendoscopy and conventional colonoscopy in the diagnosis of colorectal neoplasia. Gut Sep 27 (Epub ahead of print) 
38. Kudo S, Rubio CA, Teixeira CR et al (2001) Pit pattern in colorectal neoplasia: endoscopic magnifying view. Endoscopy 33:367-373

39. Saitoh Y, Obara T, Einami K et al (1996) Efficacy of high-frequency ultrasound probes for the preoperative staging of invasion depth in flat and depressed colorectal tumors. Gastrointest Endosc 44:34-39

40. Palazzo MGL, Canard PJM (2001) Guidelines of the French Society of Digestive Endoscopy: endoscopic mucosectomy. Endoscopy 33:187-190

41. Varadarajulu S, Tamhane A, Slaughter RL (2006) Evaluation of dextrose $50 \%$ as a medium for injection-assisted polypectomy. Endoscopy 38:907-912

42. Yamamoto H, Kawat H, Sunada K et al (2003) Successful enbloc resection of large superficial tumours of the stomach and colon using sodium hyaluronate and small-caliber-tip transparent hood. Endoscopy 35:690-694

43. Uraoka T, Fujii T, Saito Y et al (2005) Effectiveness of glycerol as a submucosal injection for EMR. Gastrointest Endosc 61:736-740

44. Feitoza AB, Gostout CJ, Burgart LJ et al (2003) Hydroxypropyl methylcellulose: a better submucosal fluid cushion for endomucosal resection. Gastrointest Endosc 57:41-47

45. Hurlstone DP, Fujii T (2005) Practical uses of chromoendoscopy and magnification at colonoscopy. Gastrointest Endoscopy Clin N Am 15:687-702

46. Hurlstone DP, Lobo AJ (2003) Resection margin 'thermal tattooing' for lateral spreading tumour resection using endoscopic mucosal resection: a new technique for assisting complete horizontal clearance. World J Surg 27:1340-1341

47. Uno Y, Munakata A (1994) The non-lifting sign of invasive colon cancer. Gastrointest Endosc 40:485-489

48. Kudo S, Kashida H, Nakajima T et al (1997) Endoscopic diagnosis and treatment of early colorectal cancer. World J Surg 21:694-701

49. Ponchon T (2001) Endoscopic mucosal resection. J Clin Gastroenterol 32:6-10

50. Okamoto H, Tanaka S, Haruma K (1996) Japanese review of complications and measure by endoscopic treatment for colorectal tumor between 1989-1993. Hiroshimaigaku 49:585-591

51. Ahmad NA, Kochman ML, Long WB et al (2002) Efficacy, safety, and clinical outcomes of endoscopic mucosal resection: a study of 101 cases. Gastrointest Endosc 55:390-396

52. Kaneko E, Harada H, Kasugai $T$ et al (1995) The results of a multi-centre analysis from 1988-1992. Gastroenterol Endosc 37:642-652

53. Kaneko E, Hanada H, Kasugai T (2000) The survey of gastrointestinal endoscopic complications in Japan (1993-1997). Gastroenterol Endosc 42:308-313

54. Fujishiro M, Yahagi N, Nakamura M et al (2006) Successful outcomes of a novel endoscopic treatment for GI tumors: endoscopic submucosal dissection with a mixture of highmolecular-weight hyaluronic acid, glycerin, and sugar. Gastrointest Endosc 63:243-249

55. Fujishiro M, Yahagi N, Kakushima N et al (2006) Successful endoscopic en bloc resection of a large laterally spreading tumor in the rectosigmoid junction by endoscopic submucosal dissection. Gastrointest Endosc 63:178-183

56. Paris Workshop Participants (2002) The Paris endoscopic classification of superficial neoplastic lesions: esophagus, stomach and colon. Gastrointest Endosc 58:S3-S43

57. Cho E, Nakajima M, Yasuda K et al (1993) Endoscopic ultrasonography in the diagnosis of colorectal cancer invasion. Gastrointest Endosc 39:521-527

58. Rosch T, Sarbia M, Schumacher B et al (2004) Attempted endoscopic en bloc resection of mucosal and submucosal tumors using insulated-tip knives: a pilot series. Endoscopy 36:788-801

59. Fujishiro M, Yahagi N, Nakamura M et al (2006) Endoscopic submucosal dissection for rectal epithelial neoplasia. Endoscopy 38:493-497

60. Shida H, Ban K, Matsumoto M et al (1992) Prognostic significance of location of lymph node metastases in colorectal cancer. Dis Colon Rectum 35:1046-1050

61. Newland RC, Chapuis PH, Pheils MT et al (1981) The relationship of survival to staging and grading of colorectal carcinoma: a prospective study of 503 cases. Cancer 47:1424-1429

62. Newland RC, Chapuis PH, Smyth EJ (1987) The prognostic value of substaging colorectal carcinoma. A prospective study of 1117 cases with standardized pathology. Cancer 60:852-857

63. Tanaka S, Haruma K, Teixeira CR et al (1995) Endoscopic treatment of submucosal invasive colorectal carcinoma with special reference to risk factors for lymph node metastasis. J Gastroenterol 30:710-717

64. Saitoh Y, Obara T, Watari J et al (1998) Invasion depth diagnosis of depressed type early colorectal cancers by combined use of videoendoscopy and chromoendoscopy. Gastrointest Endosc 48:362-370

65. Hurlstone DP, Cross SS, Adam I et al (2004) Endoscopic morphological anticipation of submucosal invasion in flat and depressed colorectal lesions: clinical implications and subtype analysis of the Kudo type V pit pattern using high-magnification-chromoscopic colonoscopy. Colorect Dis 6:369-375

66. Nagata S, Tanaka S, Haruma K et al (2000) Pit pattern diagnosis of early colorectal carcinoma by magnifying colonoscopy: clinical and histological implications. Int $\mathrm{J}$ Oncol 16:927-934

67. Roseau G, Palazzo L, Amouyal P (1990) Endoscopic ultrasonography in the preoperative evaluation of rectal cancer. Presse Med 19:1450-1453

68. Roubein LD, David C, DuBrow R (1990) Endoscopic ultrasonography in staging rectal cancer. Am J Gastroenterol 85:1391-2394

69. Oohara N, Murata Y, Kawanami C (1991) Ultrasonography in the colorectal lesion: a comparison between endoscopic ultrasonography (7.5 MHz) and sonoprobe system (20 MHz). Prog Gastrointest Endosonogr 39:221-225

70. Hurlstone DP, Brown SR, Cross SS et al (2005) High-magnification-chromoscopic-colonoscopy or high-frequency 20 $\mathrm{MHz}$ mini-probe endoscopic ultrasound staging for early colorectal neoplasia: a comparative prospective analysis. Gut 54:1585-1589

71. Wagnieres GA, Star WM, Wilson BC (1998) In vivo fluorescence spectroscopy and imaging for oncological applications. J Photochem Photobiol 68:603-632

72. Kapadia CR, Cutruzzola FW, O'Brien KM et al (1990) Laserinduced fluorescence spectroscopy of human colonic mucosa. Detection of adenomatous transformation. Gastroenterology 99:150-157

73. Haringsma J, Tytgat GNJ, Yano H et al (2001) Autofluore- 
scence endoscopy: feasibility of detection of GI neoplasms unapparent to white light endoscopy with an evolving technology. Gastrointest Endosc 53:642-650

74. Cothren RM, Richards-Kortum R, Sivak MV et al (1990) Gastrointestinal tissue diagnosis by laser-induced fluorescence spectroscopy at endoscopy. Gastrointest Endosc 36:105-111

75. Cothren RM, Sivak MV, Van Dam J et al (1996) Detection of dysplasia at colonoscopy using laser-induced fluorescence: a blinded study. Gastrointest Endosc 44:168-176
76. Chwirot BW, Kowalska M, Sypniewska N et al (1999) Spectrally resolved fluorescence imaging of colonic adenomas. J Photochem Photobiol 50:174-183

77. Wang TD, Van Dam J, Crawford JM et al (1996) Fluorescence endoscopic imaging of human colonic adenomas. Gastroenterology 111:1182-1191

78. Wang TD, Crawford JM, Feld MS et al (1999) In vivo identification of colonic dysplasia using fluorescence endoscopic imaging. Gastrointest Endosc 49:447-455 